\title{
Compactação do solo de diferentes classes texturais em áreas de produção de cana-de-açúcar
}

\author{
Renato Paiva de Lima ${ }^{1}$, Maurício Javier De León ${ }^{2}$, Anderson Rodrigo da Silva ${ }^{3}$
}

\begin{abstract}
RESUMO
O objetivo deste trabalho foi avaliar a existência de camadas compactadas, em três diferentes classes texturais de solos. O estudo foi desenvolvido em áreas, sob cultivo de cana-de-açúcar, da Fazenda Guanabara, localizada no município de Nova Olímpia, Mato Grosso, Brasil. Para coleta dos dados, foi utilizado um penetrômetro de impacto, modelo IAA/Planalsucar, para avaliação da resistência à penetração (RP), em três diferentes classes texturais (Areia Franca, Franco-Argilo- Arenosa e Muito Argilosa). O solo de classe textural franco-argilo-arenosa apresentou os maiores valores de resistência à penetração, entre as três classes. As classes texturais franco-arenosa e muito argilosa comportaram-se de forma semelhante, em todas as camadas. Houve semelhança na resistência à penetração das três classes texturais na camada $0,3-0,4 \mathrm{~m}$.
\end{abstract}

Palavras-chave: física do solo, penetrômetro, mecânica do solo.

\section{ABSTRACT}

\section{Soil compaction of different textural classes in areas of sugarcane production}

The purpose of this study was to evaluate the existence of compacted layers in three different textural classes located in production areas of sugarcane. The study was conducted in production areas of sugarcane at Fazenda Guanabara, located at municipality of New Olympia, Mato Grosso state, Brazil. Data collection was conducted using an impact penetrometer, model IAA/Planalsucar, evaluating the penetration resistance in three different texture (Loam Sandy, Sandy Clay Loam and Clay). Loam Sandy and Clay textures showed the highest penetration resistance. Loam Sandy and Clay textures behaved very similarly in all layers. There were similar values of penetration resistance of the three classes in 0.3-0.4 m layer.

Key words: soil physics, penetrometer, soil mechanics.

Recebido para publicação em 30/05/2012 e aprovado em 23/11/2012.

'Engenheiro-Agrônomo. Mestrando do Departamento de Tecnologia Rural, Universidade Federal Rural de Pernambuco, Rua Dom Manoel de Medeiros, s/n, Dois Irmãos, 52171900, Recife, Pernambuco, Brasil. renato_agro_@hotmail.com (autor para correspondência).

${ }^{2}$ Engenheiro-Agrônomo, Doutor. Departamento de Solos e Engenharia Rural, Universidade Federal da Paraíba, Rodovia BR 079, Km 12, 58397-000, Areia, Paraíba, Brasil. mauricio@cca.ufpb.br

${ }^{3}$ Engenheiro-Agrônomo, Mestre. Doutorando do Programa de Pós-Graduação em Estatística e Experimentação Agronômica, Escola Superior de Agricultura "Luiz de Queiróz", Avenida Pádua Dias, 13418-900, Piracicaba, São Paulo, Brasil. ar.silva @usp.br 


\section{INTRODUÇÃO}

A qualidade do solo é função de alguns atributos que promovem o bom desenvolvimento das raízes, tais como: infiltração e movimento de água no perfil, trocas gasosas, atividade biológica e mineralização de carbono. Todos esses atributos são, em parte, relacionados com as propriedades e os processos físicos do solo (Carvalho et al., 2008).

O impacto dos sistemas de preparo, colheita e manejo dos solos tem sido avaliado por meio de suas propriedades físicas, como a densidade, a macroporosidade (Carneiro et al., 2009; Lima et. al., 2007) e a resistência do solo à penetração (Tavares Filho \& Ribon, 2008).

Uma das propriedades físicas importantes para o manejo e estudo da qualidade física dos solos é sua resistência à penetração, uma vez que essa propriedade apresenta-se relacionada com diversos atributos do solo, indicadores do grau de compactação (Ribon \& Tavares Filho, 2008).

O tráfego intensivo de máquinas é o principal responsável pelo aumento da densidade e resistência do solo (Resende Silva, et al., 2011), diminuição da macroporosidade e condutividade hidráulica (Suzuki et al., 2007), resultando na compactação do solo e alterando o meio onde o sistema radicular desenvolve-se (Marchão et al., 2007).

Uma das culturas mais afetadas pela alteração das condições físicas do solo é a cana-de-açúcar, uma vez que, em decorrência da colheita mecanizada, a compactação pode promover reduções superiores a $50 \%$ no volume de macroporos do solo. Por sua vez, essa alteração estrutural pode comprometer a sustentabilidade dessa atividade agrícola, pois essa classe de poros determina a taxa de movimentação de água no solo (Severiano et. al., 2010).

A susceptibilidade do solo à compactação apresenta variações, em função das propriedades do solo, tais como teor de água e textura. A textura influencia o comportamento do solo, quando submetido a pressões externas, pois determina o atrito entre as partículas e o tipo de ligação entre elas. Em geral, quanto maiores as partículas do solo, menor sua compressibilidade e agregação (Macedo, et. al., 2010).

Para verificar a existência de camadas compactadas, o penetrômetro é o instrumento que, por meio do valor da resistência do solo à penetração, mede a resistência física que o solo oferece a algo que tenta se mover através dele, como uma raiz em crescimento ou uma ferramenta de cultivo (Roboredo et al., 2010; Beutler et al., 2007). Na prática, o conhecimento da resistência à penetração é importante, pois permite identificar as condições nas quais poderá ocorrer impedimento ao crescimento radicular das plantas.
Portanto, objetivou-se, com este trabalho, avaliar, por meio dos valores da resistência à penetração, a existência de camadas compactadas, em três diferentes classes texturais de solos, em áreas de produção de cana-deaçúcar.

\section{MATERIAL E MÉTODOS}

O levantamento de dados, no campo, foi realizado em fevereiro de 2010, em áreas de produção de cana-deaçúcar da Fazenda Guanabara, localizada no município de Nova Olímpia, Estado de Mato Grosso, 14²46’58" Latitude Sul e $57^{\circ} 17^{\prime} 22^{\prime \prime}$ Longitude Oeste, com altitude média de $220 \mathrm{~m}$ e precipitação anual de $1.750 \mathrm{~mm}$. A vegetação da região apresenta características de transição, do Cerrado para a Floresta Amazônica, e o relevo é evidenciado pelas Depressões do Rio Paraguai. A temperatura média anual é de $24^{\circ} \mathrm{C}$, sendo a máxima de $40^{\circ} \mathrm{C}$ e, a mínima, de $0{ }^{\circ} \mathrm{C}$.

Todas as áreas estavam ocupadas com cana-de-açúcar, em quarto corte, ou seja, os talhões que foram avaliados sofreram quatro colheitas. As áreas em avaliação receberam sistema de colheita mecanizada, com colhedoras Cameco, modelo CHT-2500, dotadas de rodado de esteiras, com massa aproximada em torno de 16,5 t. O espaçamento empregado foi de 1,5 m entre linhas de plantio. No preparo do solo, foi realizada subsolagem, uma aração e uma gradagem, para cada uma das três áreas, no ano de 2006. Para coleta dos dados, foi utilizado um penetrômetro de impacto, modelo IAA/ Planalsucar. Foram amostrados, aleatoriamente, oito pontos em cada um dos três talhões, com diferentes classes texturais, em áreas de aproximadamente 20 ha. No momento da amostragem com o penetrômetro, foram coletadas oito amostras de solo, nas camadas de 0,0-0,1 $\mathrm{m}, 0,1-0,2 \mathrm{~m}, 0,2-0,3 \mathrm{~m}$ e 0,3-0,4 m, de cada classe textural, para determinação da umidade gravimétrica do solo e da granulometria. Após a coleta, cada amostra foi pesada, no campo, e depositada em recipiente plástico, para serem transportadas até o Laboratório de Física do Solo, do Centro de Ciências Agrárias, da Universidade Federal da Paraíba, onde foram realizadas as determinações, segundo metodologia da Embrapa (1997).

Na tabulação dos dados de resistência à penetração, utilizou-se a equação 1 , acrescentando-se apenas os valores das leituras no campo (impactos. $\mathrm{dm}^{-1}$ ), pois a massa e o deslocamento do penetrômetro modelo IAA/Planalsucar já são conhecidos.

$\mathrm{RP}\left(\mathrm{kgf} / \mathrm{cm}^{2}\right)=5,6+6,89 \mathrm{~N}$

em que:

$\mathrm{RP}$ - resistência à penetração $\left(\mathrm{kgf} / \mathrm{cm}^{2}\right)$

$\mathrm{N}$ - número de impactos. $\mathrm{dm}^{-1}$ 
Para conversão da resistência à penetração, de kgf/ $/ \mathrm{cm}^{2}$ para mega pascal (MPa), utilizou-se a equação 2 (Stolf, 1990).

$\mathrm{RP}(\mathrm{MPa})=0,0980665 \mathrm{xgf} / \mathrm{cm}^{2}$

Os dados de resistência à penetração foram analisados de acordo com o modelo de análise de variância em delineamento de parcelas subdivididas em faixas, sendo conduzido em três classes texturais (Areia Franca, Franco-Argilo-Arenosa e Muito Argilosa) (Tabela 1) e, em cada classe, as determinações foram realizadas em quatro camadas (0,0-0,1 m; 0,1-0,2 m; 0,2-0,3 m; 0,3-0,4 m) e oito repetições, totalizando 96 determinações. Considerou-se como unidade observacional cada ponto amostral, em cada uma das três áreas, composta pela média aritmética dos valores obtidos pelo penetrômetro, a cada $0,1 \mathrm{~m}$ de profundidade, em um perfil total de $0,4 \mathrm{~m}$.

As médias dos tratamentos principais e dos teores de água foram comparadas pelo teste $t$. Todos os procedimentos estatísticos foram efetuados a 5\% de significância. Para as análises estatísticas, foi utilizado o software GENES, versão 2009.7.0 (Cruz, 2006).

\section{RESULTADOS E DISCUSSÃO}

Na Tabela 2, são apresentados os resultados das análises de teor de água no solo, nas camadas de 0,0-0,1 m, 0,1-0,2 m, 0,2-0,3 m e 0,3-0,4 m, para as três classes texturais. $\mathrm{O}$ teste de média aplicado aos teores de água mostra que houve diferença significativa, pelo teste $t$, para as diferentes classes texturais, em todas as camadas.

O solo de textura muito argilosa apresentou as maiores médias de teor de água, seguido do solo de textura franco-argilo-arenosa. O solo de textura areia franca apresentou as menores médias de conteúdo de água, dentre todas as classes texturais analisadas.
Na Tabela 3, observam-se os valores médios de resistência à penetração, para as três classes texturais. O solo de textura areia franca apresentou valores de resistência à penetração entre 2,0 e 4,4 MPa, com destaque para camada de $0,2-0,3 \mathrm{~m}$, que apresentou a maior média do tratamento (4,4 MPa). Os dados desta classe textural assemelham-se, estatisticamente, aos da classe de textura muito argilosa, em todas as camadas analisadas, porém, apresentam diferença significativa com relação aos do solo de textura franco- argilo- arenosa, na camada de 0,0 até $0,2 \mathrm{~m}$.

Em profundidade, o maior valor médio de resistência à penetração, no solo de textura areia franca, foi atingido na camada de 0,2-0,3 m, com as camadas 0,1-0,2 m e 0,3-0,4 m apresentando-se de forma semelhante, e, a camada de 0,0$0,1 \mathrm{~m}$, com valor ligeiramente inferior ao das demais. Estes resultados concordam com os obtidos por Dedecek \& Gava (2005), que, estudando o efeito do trânsito de equipamentos, na colheita do eucalipto, afirmam que o tráfego provocou compactação na camada de $0,0-0,3 \mathrm{~m}$, em solo arenoso, com os valores médios de resistência à penetração superando 5,0 MPa.

Para solos com teores elevados de areia, Sene et al. (1985) consideram críticos os valores de resistência à penetração que variam de 6,0 a 7,0 MPa. Portanto, o solo de textura areia franca não apresenta valores críticos de resistência à penetração, que possam causar impedimento ao desenvolvimento do sistema radicular.

Ainda, na Tabela 3, observam-se as médias de resistência à penetração do solo com classe textural francoargilo-arenosa. Verifica-se que, até a profundidade de 0,3 $\mathrm{m}$, houve diferença significativa, com relação às das demais classes texturais, sendo esta, a que apresenta as maiores médias de resistência à penetração dentre todos os tratamentos, atingindo valores de 4,7 $\mathrm{MPa}$, na camada de $0,2-0,3 \mathrm{~m}$.

Tabela 1. Classes texturais (Lemos \& Santos, 1996) e de solo (Embrapa, 2006) das áreas experimentais, Fazenda Guanabara-MT

\begin{tabular}{lcccc}
\hline \multirow{2}{*}{ Classe textural } & Classificação & \multicolumn{3}{c}{ Granulometria $\left(\mathbf{g ~ \mathbf { ~ g } ^ { - 1 }}\right)$} \\
\cline { 3 - 5 } & & Areia & Silte & Argila \\
\hline Areia Franca & Latossolo Amarelo & 830 & 30 & 140 \\
Franco -Argilosa Arenosa & Latossolo Vermelho & 600 & 80 & 320 \\
Muito Argilosa & Latossolo Vermelho & 170 & 100 & 730 \\
\hline
\end{tabular}

Tabela 2. Comparação das médias de gravimétrica do solo sob diferentes classes texturais, Fazenda Guanabara-MT

\begin{tabular}{|c|c|c|c|c|}
\hline \multirow{3}{*}{ Classe Textural } & \multicolumn{4}{|c|}{ Camadas do solo (m) } \\
\hline & $0,0-0,1$ & $0,1-0,2$ & $0,2-0,3$ & 0,3-0,4 \\
\hline & \multicolumn{4}{|c|}{ Umidade gravimétrica $\left(\mathrm{g} \mathrm{g}^{-1}\right)$} \\
\hline Areia Franca & $14 \mathrm{c}$ & $14 \mathrm{c}$ & $15 \mathrm{c}$ & $17 \mathrm{c}$ \\
\hline Franco-Argilo-Arenosa & $19 \mathrm{~b}$ & $19 b$ & $20 \mathrm{~b}$ & $20 \mathrm{~b}$ \\
\hline Muito Argilosa & $26 \mathrm{a}$ & $26 \mathrm{a}$ & $28 \mathrm{a}$ & $28 \mathrm{a}$ \\
\hline
\end{tabular}

Médias seguidas de mesma letra na coluna não diferem estatisticamente pelo teste de $t$, a $5 \%$ de probabilidade.

Rev. Ceres, Viçosa, v. 60, n.1, p. 016-020, jan/fev, 2013 
Tabela 3. Comparação das médias de Resistência à Penetração (RP, em MPa) sob diferentes classes texturais

\begin{tabular}{lllll}
\hline & \multicolumn{4}{c}{ Camadas do solo $(\mathbf{m})$} \\
\cline { 2 - 4 } Classe Textural & $\mathbf{0 , 0 - 0 , 1}$ & $\mathbf{0 , 1 - 0 , 2}$ & $\mathbf{0 , 2 - 0 , 3}$ & $\mathbf{0 , 3 - 0 , 4}$ \\
\cline { 2 - 4 } & \multicolumn{4}{c}{ Resistência à Penetração $(\mathbf{M P a})$} \\
\hline Areia Franca & $2,075 \mathrm{bC}$ & $3,626 \mathrm{bAB}$ & $4,437 \mathrm{abA}$ & $4,025 \mathrm{aAB}$ \\
Franco-Argilo- Arenosa & $2,875 \mathrm{aB}$ & $4,687 \mathrm{aA}$ & $4,787 \mathrm{aA}$ & $3,500 \mathrm{aB}$ \\
Muito Argilosa & $2,162 \mathrm{abB}$ & $3,312 \mathrm{bA}$ & $4,037 \mathrm{bA}$ & $4,200 \mathrm{aA}$ \\
\hline
\end{tabular}

Médias seguidas de mesma letra minúscula, na coluna, e maiúscula, na linha, não diferem estatisticamente pelo teste $t$, a 5\% de probabilidade.

Nesta mesma classe textural, verificam-se, também, as médias de resistência à penetração ao longo do perfil, em que há semelhança estatística entre as médias das camadas 0,1-0,2 m e 0,2-0,3 m (Tabela 3), evidenciando uma camada de maior resistência do solo, a esta profundidade. Estes resultados concordam com os encontrados por Cavalieri et al. (2009), que constataram, sob solos de textura franco- argilo-arenosa, maior concentração da resistência à penetração nas camadas a partir de $0,1 \mathrm{~m}$ de profundidade, sob tráfego de máquinas agrícolas.

Dentre as classes texturais estudadas, esta é a que se apresenta com maior distribuição das frações granulométricas, que, pelo rearranjo das partículas de diferentes tamanhos, pode ter contribuído para que a resistência à penetração atingisse os mais altos níveis, nos diferentes tratamentos.

Segundo Araújo (2004), a argila apresenta propriedade cimentante e tende a revestir e combinar-se com a fração areia, formando agregados secundários, o que, teoricamente, forçaria a formação de camadas compactadas. Pacheco \& Cantalice (2011) reforçam que solos que contêm ampla distribuição de tamanhos de partículas podem ter os espaços entre os poros maiores preenchidos por partículas menores, e, o espaço entre estas, preenchidos novamente por partículas muito finas, viabilizando a formação de camadas compactadas, quando submetidos a pressões externas.

Os valores de resistência do solo de textura muito argilosa não apresentaram diferenças significativas, com relação aos do solo de classe textural areia franca (Tabela 3), comportando-se de forma semelhante, em relação aos valores médios de resistência à penetração. Porém, apresentaram diferença significativa com relação aos do solo de textura franco- argilo- arenosa, nas camadas de 0,1-0,3 m. A maior média de resistência à penetração, nesta classe textural, foi obtida na camada de 0,3-0,4 m, atingindo 4,2 MPa.

Ao longo do perfil, os valores de resistência do solo de textura muito argilosa não apresentaram diferenças significativas, a partir da camada de $0,1 \mathrm{~m}$, mostrando-se uniformes, quanto à resistência à penetração em maiores profundidades. Pereira et al. (2002) estudaram a compactação, em diferentes sistemas de cultivo, em um solo argiloso, e constataram maiores valores de resistên- cia à penetração com o aumento da profundidade, o que demonstra ser uma característica de solos com altos teores desta fração granulométrica.

Embora este valor não tenha sido significativo com relação ao das demais classes texturais (Tabela 3), Sene et al. (1985) afirmam que, para solos com elevado teor de argila, valores de resistência à penetração acima de 2,5 MPa são consideradas críticos ao desenvolvimento das plantas. Na Tabela 3, observa-se que, apenas na camada de 0,0-0,1 m, esse valor médio não é atingido, o que poderia causar impedimento ao desenvolvimento radicular nas demais camadas que superaram 2,5 MPa.

Estudando resistência à penetração, em solos com alto teor de argila e diferentes teores de água, Assis et al. (2009) encontraram valores médios próximos a 4,0 MPa, com $23 \mathrm{~g} \mathrm{~g}^{-1}$ de água em camadas acima de $0,3 \mathrm{~m}$, concordando com valores apresentados na Tabela 3 .

\section{CONCLUSÕES}

O solo com classe textural franco-argilo- arenosa apresentou os maiores valores de resistência à penetração, entre as três classes texturais estudadas.

As classes texturais franco-arenosa e muito argilosa comportaram-se de forma semelhante em todas as camadas.

Houve semelhança na resistência à penetração das três classes texturais na camada 0,3-0,4 m.

\section{REFERÊNCIAS}

Araújo AG (2004) Estimativa e classificação da compactação do solo pelo tráfego de máquinas agrícolas através da modelagem nebulosa. Tese de Doutorado. Universidade de São Paulo, São Paulo. 224p.

Assis RL, Lazarini GD, Lanças KP \& Cargnelutti Filho A (2009) Avaliação da resistência do solo à penetração em diferentes solos com a variação do teor de água. Engenharia Agricola, 29:558-568.

Beutler AN, Centurion JF \& Silva AP (2007) Comparação de penetrômetros na avaliação da compactação de Latossolos. Engenharia Agrícola, 27:146-151.

Carneiro MAC, Souza ED, Reis EF, Pereira HS \& Azevedo WR (2009) Atributos físicos, químicos e biológicos de solo de cerrado sob diferentes sistemas de uso e manejo. Revista Brasileira de Ciência do Solo, 33:147-157.

Rev. Ceres, Viçosa, v. 60, n.1, p. 016-020, jan/fev, 2013 
Carvalho LA, Neto VJM, Silva LF, Pereira JG, Nunes WAGA \& Chaves CHC (2008) Resistência mecânica do solo à penetração (RMP) sob cultivo de cana-de-açúcar, no município de Rio Brilhante-MS. Revista Agrarian, 1:07-22.

Cruz CD (2006) Programa Genes: Biometria. Viçosa, Editora UFV. $382 \mathrm{p}$.

Cavalieri KMV, Silva AP, Arvidsson J \& Tormena CA (2009) Influência da carga mecânica de máquina sobre propriedades físicas de um Cambissolo Háplico. Revista Brasileira de Ciência do Solo, 33:477-485.

Dedecek RA \& Gava JL (2005) Influência da compactação do solo na produtividade da rebrota de eucalipto. Revista Árvore, 29:383-390.

Embrapa (1997) Manual de análises químicas de solos, plantas e fertilizantes. Brasília, Embrapa Solos. 370p.

Embrapa (2006) Sistema Brasileiro de Classificação de Solos. $2^{\mathrm{a}}$ ed. Rio de Janeiro, Embrapa-SPI. 306p.

Lemos RC \& Santos RD (1996) Manual de descrição e coleta de solo no campo. $3^{\text {a }}$ ed. Campinas, Sociedade Brasileira de Ciência do Solo. $83 \mathrm{p}$.

Lima CLR, Reichert JM, Reinert DJ, Suzuki LEAS \& Dalbianco L (2007) Densidade crítica ao crescimento de plantas considerando água disponível e resistência à penetração de um Argissolo Vermelho distrófico arênico. Ciência Rural, 37:1166-1169.

Macedo VRM, Silva AJN \& Cabeda MSV (2010) Influência de tensões compressivas na pressão de precompactação e no índice de compressão do solo. Revista Brasileira de Engenharia Agrícola e Ambiental, 14:856-862.

Marchão RL, Balbino LC, Silva EM, Santos Jr. JDG, Sá MAC, Vilela L \& Becquer T (2007) Qualidade física de um Latossolo Vermelho sob sistemas de integração lavoura-pecuária no Cerrado. Pesquisa Agropecuária Brasileira, 42:873-882.

Pacheco EP \& Cantalice JRB (2011) Compressibilidade, resistência a penetração e intervalo hídrico ótimo de um Argissolo Amarelo cultivado com cana-de-açúcar nos Tabuleiros Costeiros de Alagoas. Revista Brasileira de Ciência do Solo, 35:403-415.
Pereira JO, Siqueira JAC, Uribe-Opazo MA \& Silva SL (2002) Resistência do solo à penetração em função do sistema de cultivo e teor de água do solo. Revista Brasileira de Engenharia Agrícola e Ambiental, 6:171-174.

Resende Silva A, Dias Junior MS \& Leite FP (2011) Avaliação da intensidade de tráfego e carga de um forwarder sobre a compactação de um Latossolo Vermelho-Amarelo. Revista Árvore, 35:547-554

Ribon AA \& Tavares Filho J (2008) Estimativa da resistência mecânica à penetração de um latossolo vermelho sob cultura perene no norte do estado do Paraná. Revista Brasileira de Ciência do Solo, 32:1817-1825.

Roboredo D, Maia JCS, Oliveira OJ \& Roque CG (2010) Uso de dois penetrômetros na avaliação da resistência mecânica de um Latossolo vermelho distrófico. Engenharia Agrícola, 30:307314 .

Sene M, Vepraskas MJ, Naderman GC \& Denton HP (1985) Relationships of soil texture and structure to corn yield response to subsoiling. Soil Science Society of America, 49:422-427.

Severiano EC, Oliveira GC, Dias Junior MS, Castro MB, Oliveira LFC \& Costa KAP (2010) Compactação de solos cultivados com cana-de-açúcar: II - quantificação das restrições às funções edáficas do solo em decorrência da compactação prejudicial. Engenharia Agrícola, 30:414-423.

Stolf R (1990) Fórmulas de transformação dos dados do penetrômetro de impacto em força/unidade de área. In: Congresso Brasileiro de Engenharia Agrícola, Piracicaba. Anais, SBEA. p.825-838.

Suzuki LEAS, Reichert JM, Reinert DJ \& Lima CLR (2007) Grau de compactação, propriedades físicas e rendimento de culturas em Latossolo e Argissolo. Pesquisa Agropecuária Brasileira, 42:1159-1167.

Tavares Filho J \& Ribon AA (2008) Resistência do solo a penetração em relação ao número de amostras e ao tipo de amostragem. Revista Brasileira de Ciência do Solo, 32:487-494. 